\title{
Compressional and Shear Wave Velocities for Artificial Granular Media Under Simulated Near Surface Conditions
}

\author{
B. P. Bonner, P. A. Berge, D. Wildenschild
}

This article was submitted to the

Society of Exploration Geophysicists International Exposition and $71^{\text {st }}$ Annual Meeting, San Antonio, Texas, September 9-14, 2001

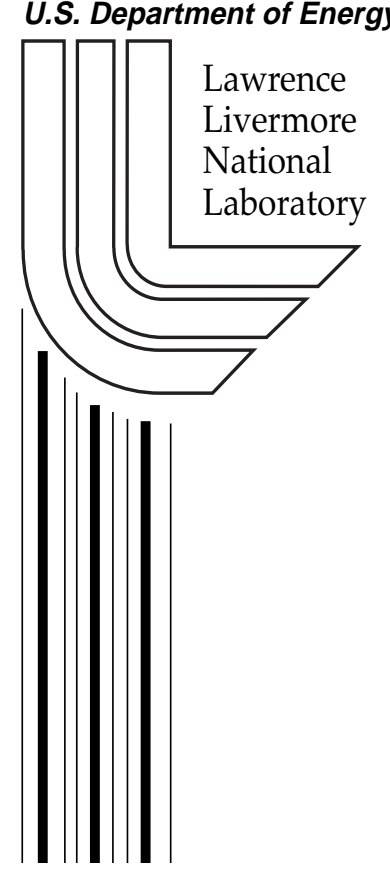

March 18, 2001 


\section{DISCLAIMER}

This document was prepared as an account of work sponsored by an agency of the United States Government. Neither the United States Government nor the University of California nor any of their employees, makes any warranty, express or implied, or assumes any legal liability or responsibility for the accuracy, completeness, or usefulness of any information, apparatus, product, or process disclosed, or represents that its use would not infringe privately owned rights. Reference herein to any specific commercial product, process, or service by trade name, trademark, manufacturer, or otherwise, does not necessarily constitute or imply its endorsement, recommendation, or favoring by the United States Government or the University of California. The views and opinions of authors expressed herein do not necessarily state or reflect those of the United States Government or the University of California, and shall not be used for advertising or product endorsement purposes.

This is a preprint of a paper intended for publication in a journal or proceedings. Since changes may be made before publication, this preprint is made available with the understanding that it will not be cited or reproduced without the permission of the author.

This report has been reproduced directly from the best available copy.

Available electronically at http://www.doc.gov/bridge

Available for a processing fee to U.S. Department of Energy

And its contractors in paper from

U.S. Department of Energy

Office of Scientific and Technical Information

P.O. Box 62

Oak Ridge, TN 37831-0062

Telephone: (865) 576-8401

Facsimile: (865) 576-5728

E-mail: reports@adonis.osti.gov

Available for the sale to the public from

U.S. Department of Commerce

National Technical Information Service

5285 Port Royal Road

Springfield, VA 22161

Telephone: (800) 553-6847

Facsimile: (703) 605-6900

E-mail: orders@ntis.fedworld.gov

Online ordering: http:/ / www.ntis.gov/ordering.htm

\section{OR}

Lawrence Livermore National Laboratory

Technical Information Department's Digital Library

http: / / www.llnl.gov/tid/Library.html 


\title{
Compressional and Shear Wave Velocities for Artificial Granular Media Under Simulated Near Surface Conditions
}

\author{
Brian P. Bonner*, Patricia A. Berge, Lawrence Livermore National Laboratory \\ Dorthe Wildenschild, Technical University of Denmark
}

\section{Summary}

Laboratory ultrasonic experiments were made on artificial soil samples in order to observe the effects of slight overburden, sand/clay ratio and pore fluid saturation on compressional and shear wave velocities. Up to several meters of overburden were simulated by applying low uniaxial stress of about $0.1 \mathrm{MPa}$ to a restrained sample. Samples were fabricated from Ottawa sand mixed with a swelling clay (Wyoming bentonite). The amount of clay added was 1 to 40 percent by mass. Most measurements were made under room-dry conditions, but some measurements were made for fully-saturated sand-clay mixtures and for partially-saturated sand samples. For the dry sand-clay samples, compressional $(\mathrm{P})$ velocities were low, ranging from about 200 to $500 \mathrm{~m} / \mathrm{s}$ for the mixtures at low stress. Shear (S) velocities were about half of the compressional velocity, about 70 to $250 \mathrm{~m} / \mathrm{s}$. Dramatic increases in all velocities occurred with small uniaxial loads, indicating strong nonlinearity. Composition and grain packing control the mechanical response at grain contacts and the resulting nonlinear response at low stresses. $\mathrm{P}$ and $\mathrm{S}$ velocities are sensitive to the amount of clay added, even at low concentrations. At these low equivalent overburden conditions, adhesion and capillarity at grain contacts affect wave amplitudes, velocities, and frequency content in the partial saturation case.

\section{Introduction}

Recent results from near surface seismic reflection, refraction, and cross hole surveys (e.g., Bachrach and Nur, 1998; Bachrach et al., 1998; Steeples, 1998; Steeples et al., 1998) have demonstrated the value of seismic methods for shallow subsurface characterization in spite of high attenuation and low seismic velocities. Analysis of seismic attributes can provide valuable constraints on subsurface lithology, porosity, fluid saturation, and permeability. These data can help guide effective in situ remediation. In particular, additional constraints provided by shear waves dramatically improve images of lithology (Bertete-Aguirre and Berge, 2001). High-quality shear velocity measurements now can be made in the field (e.g., Carr et al., 1998). This work is part of an on-going project intended to improve interpretation of geophysical field data used for interrogation of the near surface for environmental, engineering, and remote sensing applications. Laboratory measurements of ultrasonic compressional and shear wave velocities were made on unconsolidated soils at low stresses in order to confirm recent field observations of extremely low $\mathrm{P}$ velocities in shallow soils, and to provide the first-ever laboratory measurements of shear wave velocities in unconsolidated materials at very low stresses.

The approach taken in this study was to first make baseline measurements for pure quartz sand. Clay and water were then added and ultrasonic measurements were made to characterize the effects of the added second phase and pore fluid. Although the experimental methods developed here can be used for natural materials recovered from in situ, first experiments were conducted on synthetic soils so that critical parameters such as composition, porosity, and packing technique could be controlled and investigated systematically.

\section{Experimental Method and Apparatus}

Samples were fabricated from Ottawa (Illinois) sand mixed with a swelling clay. The sand was sieved to a median grain diameter of $273 \mu \mathrm{m}$. The clay was Na-montmorillonite from Wyoming, a swelling smectite. The clay was equilibrated in a $100 \%$ humid atmosphere for seven days before sample preparation to achieve reproducible water content. The clay content in the sand-clay samples was 1 to 40 percent by mass. Bulk density ranged from about 1400

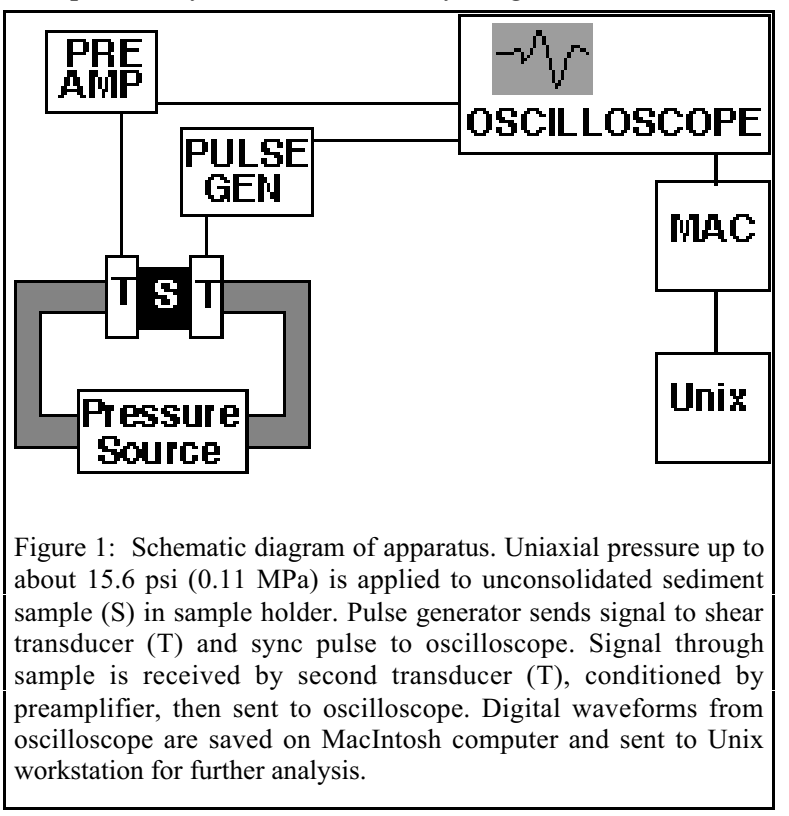


to $1700 \mathrm{~kg} / \mathrm{m}^{3}$, with a maximum of 1740 at $10 \%$ clay fraction.

The experimental method was ultrasonic pulse transmission (Sears and Bonner, 1981), modified for measurements in highly attenuating materials. An ultrasonic pulse was generated by an appropriate piezoelectric transducer at one end of the sample and received by a similar device at the other end (Figure 1). Specimens were $44.9 \mathrm{~mm}$ long and $47 \mathrm{~mm}$ in diameter. After loading the sample to simulate overburden conditions, the transit time was determined by high-speed electronics after the arrivals of the compressional and shear waves were identified. High attenuation in soils requires improvements to the standard techniques. The transmitting transducer was driven with unusually high voltages, approaching the dielectric breakdown. The transducers were operated at frequencies at the low end of the available range, about 100 to $500 \mathrm{kHz}$. A low noise, high gain preamplifier was needed and extensive signal averaging was used to improve the signal to noise ratio. High insertion loss sample containers were required to suppress arrivals that travel around the sample to obscure true arrivals (Bonner et al., 1999). The sample containers provided over $100 \mathrm{db}$ insertion loss to control leakage of ultrasound. The sample assemblies were closed with latex membranes that transmitted sound from the transducer and contained the soil mixture. Accuracy was limited to $20 \%$ at the lowest stresses near 1 psi $(7 \mathrm{kPa})$, but improved with signal amplitude to about $3 \%$ for compressional waves and $10 \%$ for shear waves at higher stresses.

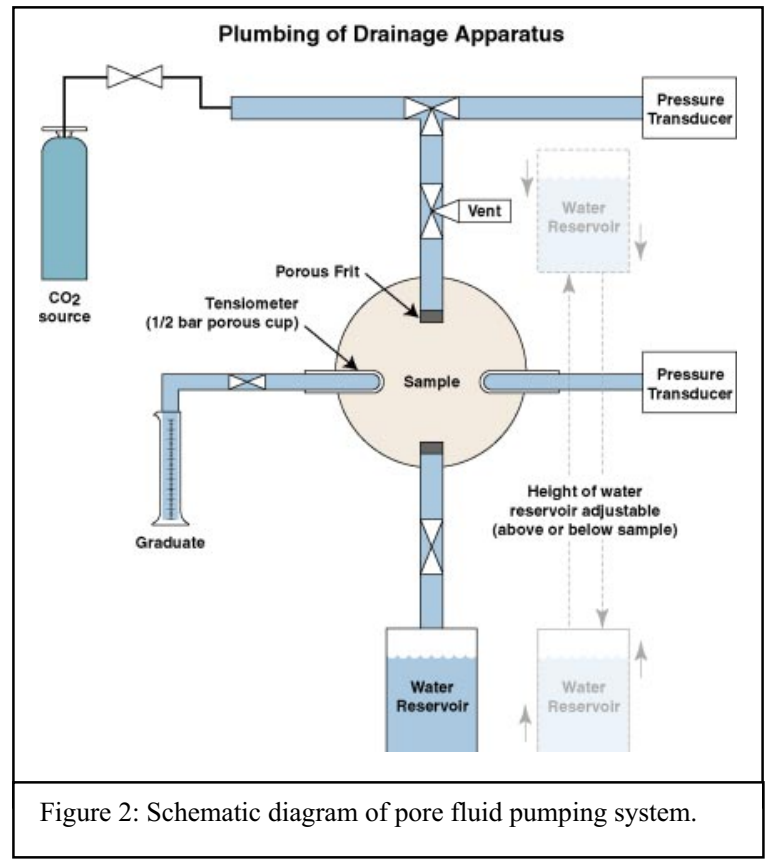

Up to several meters of overburden were simulated by applying low uniaxial stress of about $0.1 \mathrm{MPa}$ to the sample using a pneumatic system. Although the sample sleeve was not perfectly rigid, the internal stress in the sample approximately corresponded to the uniaxial strain condition. Pore fluid pressures, applied using a regulated gas tank (Figure 2), could be increased beyond the sample bubble pressure to expel water and produce partial saturation. Tensiometers were used to measure the pressure in the continuous aqueous phase when the sample was partially saturated. The difference between applied and water phase pressures is the capillary pressure.

\section{Results and Discussion}

Waveforms for samples with pure Ottawa sand and sand with $3 \%$ clay (not shown) were controlled by differences in clay cementation and water saturation. The waveform for dry sand had an amplitude ratio for shear to compressional pulses of about 1.7 . When $3 \%$ clay was added to the sand, the shear pulse grew in relative amplitude and steepness, indicating higher frequency content. The $\mathrm{S}$ to $\mathrm{P}$ amplitude ratio increased to about 4.5. Both observations are consistent with a relative decrease in shear attenuation. Details of saturation effects, including the effect of pore fluid chemistry on clay-bearing samples, will not be addressed in this paper, but the changes for saturated sand with $3 \%$ clay relative to the dry sample were dramatic. The compressional velocity increased by a factor of 4 to 5 , to approximately the velocity for water, $1500 \mathrm{~m} / \mathrm{s}$. The compressional wave dwarfed the shear arrival, which was difficult to determine and diminished to near the amplitude observed in the dry sample. When saturated, the sample behavior was similar to that of a suspension, in which the grain framework exerts minimal effect on the velocities.

Measurements of the compressional velocity for pure sand show the effect of small uniaxial load on velocity when the samples were prepared using different packing methods (Figure 3). For a hand-packed sample, velocity increases rapidly with load. Compaction by vibration eliminates much of the nonlinear response, and cycling to full loads slightly increases the $\mathrm{P}$ velocity. It is important to note that density does not increase appreciably during the loading cycle, so that the velocity increases are mainly due to minor rearrangements of the grains, resulting in improved contact.

Compressional velocities are not in general a monotonic function of clay content for the sand-clay mixtures (Figure 4). Compressional velocity increases as clay cements the sand grains in the dry samples and initially fills porosity. $\mathrm{P}$ velocity then decreases when the sample behavior is controlled by a continuous clay matrix. The behavior is similar to that reported for the sand-clay system at higher 
pressure (Marion et al., 1992). S velocity is not as sensitive to clay content, showing a decreasing monotonic trend.

Velocities were determined during forced drainage to observe the behavior of partially saturated samples. For low simulated overburden pressures, capillary forces can be of the same order as the externally applied stress, making it necessary to measure capillary pressures as the pore fluid is expelled. The measured relationship between capillary pressure and water content for pure Ottawa sand is given by the retention curve (Figure 5). The retention curve can also be used to estimate water content from equilibrium capillary pressures. Waveforms illustrating differences that arise as saturated samples are drained are presented in Figure 6. Corresponding velocities are given in Table 1. Maximum velocities for that sample were reached after about six months of drying.

\section{Conclusions}

Laboratory compressional velocities are lower than typical field values observed at greater depths but in the range typically observed at shallow depths (e.g., Bachrach and Nur, 1998; Bachrach et al., 1998; Steeples et al., 1998). Dramatic increases in all velocities occur with small uniaxial loads, indicating strong nonlinearity of the ultrasonic properties. Composition and grain packing contribute to the mechanical response at grain contacts and the nonlinear response at low stresses. Velocities are sensitive to the amount of clay added, even at low concentrations. Measured $\mathrm{P}$ velocities for sand-clay mixtures are not monotonic functions of clay content, but depend on microstructure of the mixture. Adding clay increases the shear amplitude dramatically with respect to compressional amplitude. At low equivalent overburden conditions, adhesion and capillarity at grain contacts affect wave amplitudes, velocities, and frequency content for the partially saturated case.

\section{References}

Our data are available at the URL www.1lnl.gov/ees/esd/expgeoph/Berge/EMSP/.

Bachrach, R., and Nur, A., 1998, High-resolution shallowseismic experiments in sand, Part I: Water table, fluid flow, and saturation, Geophysics, 63, 1225-1233.

Bachrach, R., Dvorkin, J., and Nur, A., 1998, Highresolution shallow-seismic experiments in sand, Part II: Velocities in shallow unconsolidated sand, Geophysics, 63, 1233-1284.

Bertete-Aguirre, H., and Berge, P. A., 2001, Recovering soil distributions from seismic data using laboratory velocity measurements, submitted to the Journal of Environmental and Engineering Geophysics.

Bonner, B. P., Boro, C., and Hart, D. J., 1999, Antiwaveguide for ultrasonic testing of granular media under elevated stress, LLNL Patent disclosure IL-10607, and patent application, DOE Patent Docket No. S-94-182, October 28, 1999.

Carr, B. J., Hajnal, Z., and Prugger, A., 1998, Shear-wave studies in glacial till, Geophysics, 63, p 1273-1284.

Marion, D., Nur, A., Yin, H., and Han, D., 1992, Compressional velocity and porosity in sand-clay mixtures, Geophysics, 57, 554-563.

Steeples, D. W., 1998, Shallow seismic reflection sectionIntroduction, Geophysics, 63, 1210-1213.

Steeples, D. W., Baker, G. S., and Schmeissner, C., 1998, Toward the autojuggie: Planting 72 geophones in 2 seconds (abstract): Eos, Trans. Am. Geophys. Un., 79, Fall Meeting Supplement, F650-651.

Sears, F. M., and Bonner, B. P., 1981, Ultrasonic attenuation measurement by spectral ratios utilizing signal processing techniques, IEEE Transactions on Geoscience and Remote Sensing, GE-19, 95-99.

\section{Acknowledgements}

This work was performed under the auspices of the U.S. Department of Energy by the University of California Lawrence Livermore National Laboratory under contract W-7405-ENG-48 and supported specifically by the Environmental Management Science Program of the Offices of Environmental Management and Science.

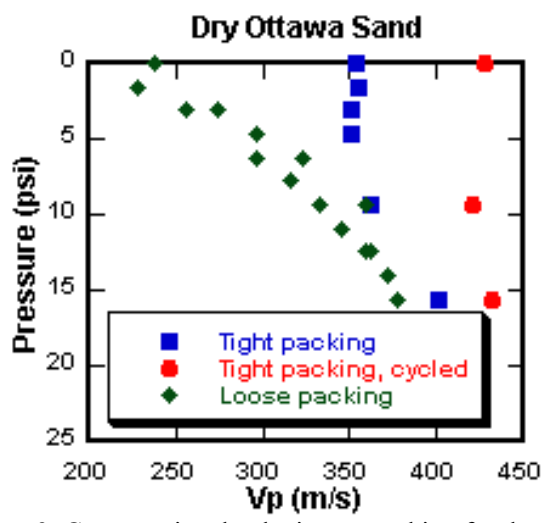

Figure 3: Compressional velocity vs. packing for dry sand. 


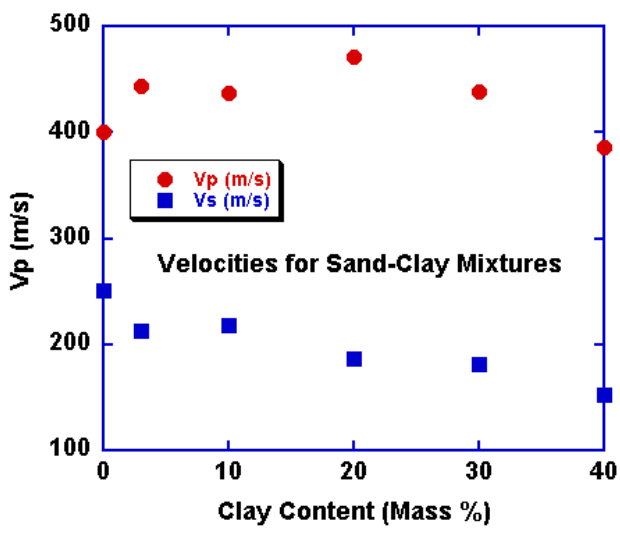

Figure 4: Velocity vs. clay content for dry sand-clay mixtures.

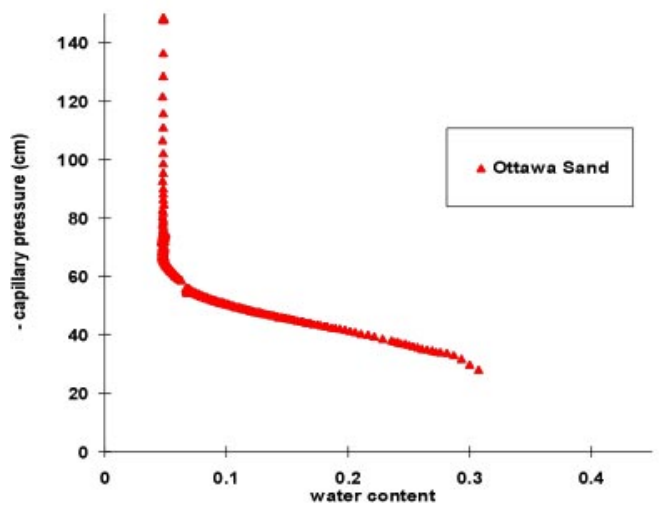

Figure 5: Water retention curve for sand sample.

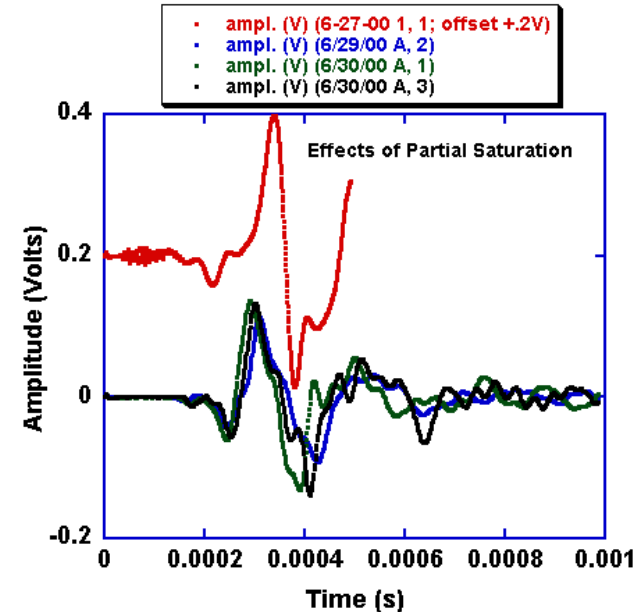

Figure 6: Waveforms during drainage of sand sample.

\begin{tabular}{|c|c|c|c|}
\hline \multicolumn{4}{|c|}{$\begin{array}{c}\text { P and S Wave Velocities for } \\
\text { Partially Saturated Sand Samples } \\
\text { with 0.04 MPa Load }\end{array}$} \\
\hline Waveform & $\mathrm{Vp}(\mathrm{m} / \mathrm{s})$ & $\mathrm{Vs}(\mathrm{m} / \mathrm{s})$ & Notes \\
\hline Sample 1: & & & \\
\hline $6 / 27 / 00 \# 1$ & $375 \pm 75$ & $232 \pm 6$ & $\begin{array}{c}\mathrm{Vp}=1500 \pm \\
40 \text { through } \\
\text { sat. patches }\end{array}$ \\
\hline Sample A: & & & \\
\hline $6 / 29 / 00 \# 2$ & $357 \pm 30$ & $214 \pm 10$ & Saturated \\
\hline $6 / 30 / 00 \# 1$ & $308 \pm 10$ & $214 \pm 10$ & $\begin{array}{c}\text { Draining } \\
\text { (capillary } \\
\text { press. }=35 \\
\text { cm) }\end{array}$ \\
\hline $6 / 30 / 00 \# 3$ & $326 \pm 10$ & $204 \pm 6$ & $\begin{array}{c}\text { Draining } \\
\text { (cap. } \\
\text { Press. }=44 \\
\text { cm) }\end{array}$ \\
\hline $12 / 7 / 00$ & $349 \pm 8$ & $249 \pm 20$ & Dried \\
\hline
\end{tabular}

